\title{
Canadian Pharmacare: Looking Back, Looking Forward
}

\section{L'assurance médicaments au Canada : coup d'œil sur le passé, regard vers l'avenir}

\author{
क्ष \\ STEVEN G. MORGAN, PHD \\ Associate Professor and Associate Director, Centre for Health Services and Policy Research \\ School of Population and Public Health \\ University of British Columbia \\ Vancouver, BC \\ JAMIE R. DAW, MSC \\ Policy Analyst, Centre for Health Services and Policy Research \\ School of Population and Public Health \\ University of British Columbia \\ Vancouver, BC
}

\begin{abstract}
Despite Canadians' pride in medicare and the values underpinning it, the system is conspicuously incomplete. Universal public health insurance in Canada ends as soon as a patient is handed a prescription to fill; yet prescription drugs are the second largest component of health system costs. We look back at key moments in Canadian healthcare history that shaped our pharmacare system - or lack thereof. We look forward to changes in demography and technology that will increase the need for pharmacare reform in the near future. We conclude that meaningful public engagement in pharmacare design may generate the clarity of goals and level of political support needed should windows of policy opportunity open again.
\end{abstract}




\section{Résumé}

Malgré la fierté des Canadiens face à l'assurance médicaments et aux valeurs qui la soustendent, le système est manifestement incomplet. L'assurance santé publique universelle au Canada prend fin dès lors qu'un patient reçoit une ordonnance, et ce, même si les médicaments sur ordonnance constituent le deuxième plus grand volet des coûts du système de santé. Nous jetons un coup d'oeil sur les grands moments de l'histoire des soins de santé au Canada, qui ont donné forme à l'assurance médicaments - ou à ses lacunes. Nous considérons les changements démographiques et technologiques qui accentueront rapidement la nécessité d'une réforme de l'assurance médicaments. Nous en concluons qu'un engagement public significatif dans la conception de l'assurance médicaments pourrait aider à clarifier les objectifs et le soutien politique nécessaire, dans la mesure où une conjoncture politique favorable se présente de nouveau.

\section{(67 Edicare" - as it is affectionately known - is a cornerstone of Canadian identity: a public health insurance system that covers virtually all
of the cost of medically necessary hospital care, diagnostic tests and physi-} cian services for every Canadian, regardless of age, income or province of residence. Canadians' pride in this system derives from the values that it represents: most fundamentally, that access to healthcare should be based solely on need and that the cost of that care should be shared among all members of society.

While opinion polls suggest that Canadians' support of medicare has remained more or less constant since its inception, the healthcare system has not. Notable changes in healthcare technology have occurred. One of the most dramatic has been the increased availability and use of prescription medicines to treat a wide range of medical conditions in the community setting. Owing to the increased use and cost of medicines outside hospitals, total spending on prescription drugs in Canada grew from $\$ 3.5$ billion in 1980 to $\$ 27.2$ billion in 2011 - expressed in inflation-adjusted year-2011 dollars (CIHI 2011, 2012). Over that period, prescription drugs used outside hospitals grew from $5.8 \%$ to $13.6 \%$ of total healthcare spending in Canada.

Prescription drugs are medical treatments that are sufficiently potent and used in the treatment of sufficiently complex medical conditions that their purchase requires - by law - professional oversight in diagnosis, product selection and dispensation. With the exception of a few drugs for lifestyle conditions, appropriately prescribed prescription drugs would generally seem to fit the definition of "medically necessary" care. Yet, owing to the structure of our medicare system, universal public health insurance in Canada ends as soon as a patient is handed a prescription to fill.

There is essentially no pharmacare in Canada's medicare system. What we have is a varied and incomplete patchwork of federal, provincial and territorial drug plans that function alongside voluntary private insurance for those able to attain and afford it (Daw and Morgan 2012; Grootendorst 2002). In this system - or lack thereof - many Canadians bear considerable 
out-of-pocket costs for the prescriptions they fill, and many are simply unable to afford the medicines they are prescribed (Law et al. 2012; McLeod et al. 2011).

If Canadian medicare is a source of national pride, then Canadian pharmacare should be a source of national embarrassment. Canada is the only country with a universal health insurance system that excludes coverage of prescription drugs. This conspicuous omission - including the misalignment of underlying values pertaining to medicare versus medically necessary prescription drugs - was not planned. Our pharmacare system is an accident of history that no sensible planner would design if given the choice to start over again today. It is a policy compromise with shortcomings that have long been identified.

\section{Looking Back}

The idea of a universal pharmacare program for Canada is an old one. Prescription drug coverage was part of comprehensive national healthcare proposals discussed in Canada as far back as the 1940s (Taylor 2009). However, while key comparators - such as Britain - chose to implement universal coverage for hospital care, physician services and prescription medicines in tandem, the path to developing Canada's health insurance system would be one of "policy in stages" (Boothe 2010: 158). National standards for universal hospital insurance were established first with the Hospital Insurance and Diagnostic Services Act of 1957; followed by standards for medical insurance under the Medical Care Act of 1966. The Hall Commission, which had been a catalyst for the Medical Care Act, recommended that national pharmacare follow (Canada 1964).

There was some logic to this sequencing. First, hospital and medical care were far more important components of healthcare and related costs at the time. If resource constraints, federal-provincial politics and operational pragmatism required that health insurance be built in stages, hospital and medical care were the stages to begin with. Secondly, though the scale of spending on medicines was small by today's standards, pharmaceutical use and costs were growing rapidly as a result of the post-war therapeutic revolution (Canada 1963). Indeed, the Hall Commission's report focusing on prescription drugs noted the specific challenge of establishing a drug benefit program in the face of "excessive patient demand, excessive prescribing, too many repeat prescriptions, [and] the lack of historic plateau or benchmark of use or average prescription price ..."(Canada 1965). The recommendation was, in effect, for policy makers to wait for pharmaceutical spending to plateau before expanding medicare to include pharmacare.

No federal legislation regarding pharmacare followed, even though spending on medicines in Canada - and around the world - slowed through the 1970s. Without a national standard, each of the provinces independently developed its own drug insurance program over the 1970s and 1980s. With the exception of Saskatchewan's pharmacare program - which was a universal, comprehensive drug benefit from 1975 through 1987 (Saskatchewan Health 2010) - early provincial drug insurance programs were not generally designed as extensions of medicare. Rather, provincial drug benefit programs arose primarily as subsidy programs for society's most vulnerable population subgroups: social assistance recipients and the 
elderly (Grootendorst 2002). Indeed, in some provinces - such as British Columbia (British Columbia 2004) - public drug benefits originated in government departments responsible for income assistance, not healthcare. This, too, had some logic.

The 1970s was a time when most prescription drugs used outside the hospital setting were medicines prescribed for common, acute conditions such as infection (Temin 1980). Moreover, as Canada had strengthened compulsory licensing provisions related to drug patents in 1969, medicines in Canada were comparatively affordable by international standards owing to generic competition against patent-holding manufacturers (Canada 1985). Individuals were generally not at significant financial risk for very high-cost or chronic medicine needs. Consequently, developing government programs as a form of targeted assistance simply ensured that those with the fewest means to pay for medicines could afford the stillmodest costs required of them.

Times changed. Beginning in the late 1970s, the pharmaceutical industry experienced a scientific revolution that drove up both the average use and cost of prescription drugs (Mowery 2004; Temin 1980). Drug development was driven forward by simultaneous advances in imaging technologies, which furthered scientific understanding of biological targets of potential therapeutic value, and in chemical synthesis and screening technologies: this was the era of "rational drug design." The potential health benefits from the wave of new drugs being developed were considerable. So, too, were the financial implications. Pharmaceuticals represented the fastest-growing component of healthcare costs from the mid-1980s through the late 1990s. They became the second-largest component of healthcare spending in Canada in 1997 - surpassing all spending on physicians' services that year and every year since (CIHI 2012).

With the use and cost of prescription drugs increasing rapidly, policy elites returned to the question of Canadian pharmacare in the 1990s. The 1997 National Forum on Health identified two key problems with the limited nature of provincial drug benefits (Canada 1998a). First, many non-seniors were believed to be either under- or un-insured for necessary medicines. Secondly, the existence of many private and public payers for medicines in each province was believed to be reducing purchasing power relative to that which could be exercised by a universal insurance program. The National Forum on Health therefore called for a universal first-dollar pharmacare program that would resemble the coverage offered for hospital and medical care in Canada (Canada 1997).

The prospects of reform following the National Forum on Health appeared dead as early as January 1998, when the federal government hosted a Conference on National Approaches to Pharmacare in Saskatchewan. Reports commissioned and promoted by the pharmaceutical industry had, by that time, created a sense that Canada could not afford a public pharmacare program owing to the increased costs and lost jobs in the insurance industry (Palmer D'Angelo Consulting 1997: 26). Even Health Minister Alan Rock's opening remarks at the 1998 conference appeared to emphasize the fact that, despite the recommendations of the National Forum on Health, a comprehensive program was not on the table - at least in the short run: 
In an ideal world, were the slate clean and money not a factor, few would doubt that a first dollar, publicly-funded, single payer universal system would be the best outcome. It would be the least expensive to society as a whole. And it would be the most fair. It would also follow through on the original recommendation of Emmett Hall's 1964 Commission on Health Care: namely, that the national plan be expanded, over time, to include, among other things, prescription drugs. But, we do not, of course, live in an ideal world, with that clean slate and unlimited money. (Canada 1998b)

While financial pressures were clearly an issue, it is also likely that Quebec's 1997 passage of compulsory private insurance for prescription drugs also made progress on national reforms difficult, if not untenable, at the time (Pomey et al. 2007).

No federal legislation pertaining to pharmacare followed from the National Forum on Health recommendations. But calls for pharmacare reform resurfaced by 2002, this time from Roy Romanow's report of the Commission on the Future of Health Care in Canada and Michael Kirby's report on behalf of the Senate Standing Committee on Social Affairs (Canada 2002a,b). Those reports focused primarily on stitching the regional gaps in catastrophic coverage for non-seniors - which was available in all provinces except those in Atlantic Canada. Both reports recommended minimum standards for covering Canadians against exceptionally high drug expenses. At least in the case of Romanow's recommendation, this was a deliberate attempt at consensus building through incremental pharmacare reform (Forest 2004).

Despite calls for change, there has been little expansion of provincial drug plans across Canada (Daw and Morgan 2012). Provincial governments financed $43 \%$ of total spending on prescription drugs in 1990, and this share changed little over the subsequent 20 years: it was $40 \%$ in 2010 (CIHI 2012).

There have, however, been changes in the structure of drug coverage offered by several provinces that will, if left unchanged, result in a declining share of prescription drug spending that is publicly financed in coming years. An increasing number of provinces are replacing comprehensive benefits for senior citizens with income-based, catastrophic drug coverage just as was historically offered for the general population. Changes of this nature have occurred in Saskatchewan (1993), Manitoba (1996) and British Columbia (2003) (Daw and Morgan 2012; Grootendorst 2002). With its 2012 budget, Ontario announced changes that signal the beginning of income-testing of the provinces drug program for seniors (Ontario 2012). Across the provinces currently offering income-based catastrophic drug plans, deductibles for households with median income levels range from 3\% to $13 \%$ of household income (Daw and Morgan 2012). Such deductibles are equal to roughly $\$ 2,000$ to $\$ 9,000$ for an average family today and, for the chronically ill, must be paid year after year (Hanley and Morgan 2009).

\section{Looking Forward}

Population aging is adding pressures to pharmacare programs that reinforce the trend towards catastrophic coverage. Specifically, as baby boomers turn 65 in provinces with age-based phar- 
macare - such as Ontario, Alberta and the Atlantic provinces - their drug costs shift from being a largely private liability to a largely public one. Societal costs of their medicines do not change dramatically; however, the source of financing does. Avoiding the public liability associated with an age-based entitlement to pharmacare was a stated motivation for the elimination of British Columbia's drug plan for seniors in 2003 (Morgan and Coombes 2006). It is also likely to motivate further reforms to seniors' drug programs in Canada if governments focus primarily on controlling public drug expenditures rather than addressing the societal burden of total drug expenditures.

Retrenchment of public drug benefits is occurring against a backdrop of dramatic changes in the global pharmaceutical marketplace. In particular, the pharmaceutical industry is in the midst of a transformation from the era of the blockbuster drug - developed and sold at moderate costs for large segments of the population - to the era of the niche-buster drug - developed for very specific population groups, often those with serious unmet health needs (Aitken et al. 2009). These changes create opportunities and challenges for policy makers.

While the industry makes this transition in drug development, relatively few new medicines are entering into the therapeutic markets that dominated drug sales over the last 20 years. The decline in new entrants into such markets means that there are relatively few remaining brand-name drugs to capture market shares as previous blockbusters lose patent protection. The financial consequences of this trend are dramatic: drugs with combined total global sales of USD $\$ 142$ billion will lose patent protection between 2010 and 2014 (IMS Health 2010). This opportunity is a major challenge for Canada because our multi-payer environment for prescription drugs precludes the use of certain policies - such as tendering - that can drive generic drug costs down considerably lower than has thus far been achieved here (Law and Morgan 2011).

As the pharmaceutical industry focuses on development of specialized medicines, other policy challenges also emerge. The threshold for defining a "high-cost" drug has risen from hundreds, or perhaps thousands, of dollars per patient per year to hundreds of thousands of dollars per patient per year. For example, breakthrough AIDS treatments brought to market in the 1990s were priced on the order of $\$ 5,000$ to $\$ 10,000$ per patient per year (Flexner 1998). At the time, those costs were considered extraordinary and even difficult to justify, despite the fact that the medicines proved to be life-saving. Today, the price tags for new drugs are an order of magnitude higher. As of 2010, Forbes magazine estimated that nine medicines were priced at more than USD $\$ 200,000$ per patient per year (Herper 2010). For example, in January 2012, the US FDA approved ivacaftor for the treatment of cystic fibrosis in patients with a specific genetic mutation, G551D. The drug, which must be taken on an ongoing basis, improves lung function by an average of roughly $12 \%$ for the estimated $4 \%$ of cystic fibrosis patients with G551D. It is priced at USD $\$ 294,000$ per patient per year (Davis et al. 2012; Rockoff and Corbett Dooren 2012). The approval of drugs of this sort is potentially good news for patients but is also putting individuals, private drug plans and even governments under significant financial strain.

Predictions are that current trends towards development of specialized medicines will result in an increasing number of extraordinarily high-cost drug treatments, raising the pros- 
pect that the costs of covering such medicines may be too high for some systems of financing to bear (Evans 2007). Canada's current pharmacare system is not capable of handling these pressures equitably and efficiently. The high deductibles of catastrophic public drug programs are tantamount to an annual tax on the small groups of people for whom emerging therapies are medically necessary. Moreover, private insurers cannot be relied on to fill the gap. Neither private insurance companies nor sponsors of the plans they provide are charities. They must pass costs of insured medicines used back onto the groups being insured. If the insurance is at the individual level, that means passing the costs right back to the patient by way of risk-rated premiums - which will be as unaffordable as the drugs needed on a year-to-year basis for those with chronic needs. If insurance is obtained through an employment group, this means passing costs back onto the employer or employees - creating adverse labour market effects and premium escalation that can lead to insurance market collapse (Hurley 2010). Either way, there is a real risk that our patchwork system will fail as a safety net.

\section{Conclusion}

The paradoxical adage is worryingly fitting in regard to Canadian pharmacare: it is the program of Canada's future - as it always has been and always will be. For over 60 years, independent experts and government commissions have concluded that universal pharmacare for medically necessary prescription drugs is the ideal option for achieving equity and efficiency. By one recent estimate, universal pharmacare could save up to $\$ 10$ billion per year while providing more equitable access to necessary medicines (Gagnon and Hebert 2010). Yet we cannot seem to get from "here" to "there."

Costs are a commonly cited barrier to change - including by us (Morgan and Willison 2004). One can point to the end of Saskatchewan's universal pharmacare program as evidence that such a program is not sustainable. When Saskatchewan had a universal, comprehensive pharmacare program - from 1975 to 1987 - real per capita pharmaceutical expenditures in the province grew by $77 \%$, which was slightly above the national average of $65 \%$; however, real per capita pharmaceutical expenditure in Ontario grew by $89 \%$ during the same period (CIHI 2011). More generally, in comparison to Canada, pharmaceutical spending is lower and has been growing at a slower rate in countries with universal coverage achieved through a wide variety of financing mechanisms, including Australia, Denmark, France, Germany, the Netherlands, New Zealand, Norway, Sweden, Switzerland and the United Kingdom (Squires 2011). It might then be suggested that sustainability is especially difficult in Canada because each of the provinces needs to avoid cost controls that could threaten local research and development investment. Fortunately, such an argument - about provinces needing to compete for industrial development through pharmaceutical coverage and pricing policy - is inconsistent with both theory and evidence (Morgan and Cunningham 2008). It is also false at a national level: for the past nine years, the pharmaceutical industry has failed to meet its promise of investing $10 \%$ of pharmaceutical sales in Canadian research and development (PMPRB 
2012), promises made when Canada abolished its policy of granting compulsory licensing for drug patents in 1987 (Grootendorst and Di Matteo 2007; Lexchin 1993).

This is not to say that costs are not considerable; rather, it is to point out that costs cannot be "the" answer to the policy paradox. Pharmacare policy development in Canada has thus far been a series of compromises, a process of "muddling through" with incremental policy changes adaptive to particular circumstances - including the influences of financial constraints, policy institutions, affected interests and political will. As we have not achieved substantial pharmacare expansion despite the calls of numerous government commissions and committees, perhaps it is time to regroup and rethink strategies. Yes, pharmacare is a complex file. There is a lot at stake and many considerations that need to be addressed, including access, appropriateness, safety, equity, evidence, politics and innovation. Further, there are many actors with very specific perspectives - not just the pharmaceutical and insurance industries, but also the medical and pharmacy professions, clinical and economic experts, disease advocacy groups, governments and others. All these considerations and actors can make reform difficult, but not impossible.

As a first step towards reform, Canadian researchers and policy elites should turn to the public to complete a task described by Health Minister Alan Rock during his sobering remarks at the 1998 Conference on National Approaches to Pharmacare. The minister suggested that the policy process "might benefit from a consideration of the basics - where we want to get to and why" [emphasis in original] (Canada 1998b). This will require a serious

dialogue with Canadians, informed by the best available evidence about the issues at stake and options for addressing them.

Eliciting answers to these questions from Canadians is not just an academic exercise. Doing so may help to establish the clear and principled vision needed for reform - a vision that could provide for Canadian pharmacare what Tommy Douglas and Emmett Hall provided for Canadian medicare. With the sector undergoing such profound and rapid changes, now is the time to answer these questions. Should a window of opportunity for pharmacare reform be available again soon, it would be a shame for policy makers to lack the vision and mandate required for change.

\section{REFERENCES}

Aitken, M., E.R. Berndt and D.M. Cutler. 2009.“Prescription Drug Spending Trends in the United States: Looking Beyond the Turning Point." Health Affairs (Millwood) 28(1): w151-60.

Boothe, K. 2010. Pharmaceutical Programs and Social Policy Development: Comparing Canada, Australia and the UK. $\mathrm{PhD}$ dissertation, University of British Colombia.

British Columbia. 2004. Pharmacare Trends 2003. Victoria: BC Ministry of Health Services.

Canada. 1963. Report Concerning the Manufacture, Distribution and Sale of Drugs. Ottawa: Department of Justice.

Canada. 1964. Royal Commission on Health Services. Ottawa: Queen's Printer.

Canada. 1965. Provision, Distribution and Cost of Drugs in Canada: Royal Commission on Health Services. Ottawa: Queen's Printer.

Canada. 1985. Report of the Commission of Inquiry on the Pharmaceutical Industry. Ottawa: Supply and Services Canada. 
Canada. 1997. Canada Health Action: Building on the Legacy. Ottawa: National Forum on Health.

Canada. 1998a. "Directions for a Pharmaceutical Policy in Canada." Canada Health Action: Building on the Legacy. Synthesis Reports and Issues Papers, Volume II. Ottawa: National Forum on Health.

Canada. 1998b. Speaking Notes for Allan Rock, Minister of Health, at the Conference on National Approaches to Pharmacare, Saskatoon, Saskatchewan. Ottawa: Health Canada.

Canada. 2002a. "Expanding Coverage to Include Protection against Catastrophic Prescription Drug Costs." In The Health of Canadians - The Federal Role: Volume Six, Recommendations for Reform (Chapter 7). Ottawa: Standing Senate Committee on Social Affairs, Science and Technology.

Canada. 2002b. "Prescription Drugs." In Building on Values: The Future of Health Care in Canada - Final Report (Chapter 9). Saskatoon: Commission on the Future of Health Care in Canada.

Canadian Institute for Health Information (CIHI). 2011. National Health Expenditure Trends, 1975 to 2011. Ottawa: Author.

Canadian Institute for Health Information (CIHI). 2012. Drug Expenditure in Canada, 1985-2012. Ottawa: Author.

Davis, P.B., U. Yasothan and P. Kirkpatrick. 2012."Ivacaftor." Nature Reviews. Drug Discovery 11(5): 349-50.

Daw, J.R. and S.G. Morgan. 2012. "Stitching the Gaps in the Canadian Public Drug Coverage Patchwork? A Review of Provincial Pharmacare Policy Changes from 2000 to 2010." Health Policy 104(1): 19-26.

Evans, J.P. 2007. "Health Care in the Age of Genetic Medicine." Journal of the American Medical Association 298(22): 2670-72.

Flexner, C. 1998. “HIV-Protease Inhibitors.” New England Journal of Medicine 338(18): 1281-93.

Forest, P.-G. 2004. “To Build a Wooden Horse... Integrating Drugs into the Public Health System.” HealthcarePapers 4(3): 22-26.

Gagnon, M. and G. Hebert. 2010.“The Economic Case for Universal Pharmacare." Retrieved July 4, 2012. <http://pharmacarenow.ca/wp-content/uploads/2010/09/Universal-Pharmacare-Report-e.pdf >.

Grootendorst, P. 2002."Beneficiary Cost Sharing Under Canadian Provincial Prescription Drug Benefit Programs: History and Assessment." Canadian Journal of Clinical Pharmacology 9(2): 79-99.

Grootendorst, P. and L. Di Matteo. 2007. “The Effect of Pharmaceutical Patent Term Length on Research and Development and Drug Expenditures in Canada." Healthcare Policy 2(3): 63-84.

Hanley, G.E. and S. Morgan. 2009. “Chronic Catastrophes: Exploring the Concentration and Sustained Nature of Ambulatory Prescription Drug Expenditures in the Population of British Columbia, Canada." Social Science and Medicine 68(5): 919-24.

Herper, M. 2010."The World's Most Expensive Drugs." Forbes.com. Retrieved July 4, 2012. <http://www.forbes. com/2010/02/19/expensive-drugs-cost-business-healthcare-rare-diseases.html >.

Hurley, J. 2010. Health Economics. Toronto: McGraw-Hill Ryerson.

IMS Health. 2010 (April 23).“IMS Forecasts Global Pharmaceutical Market Growth of 5-8\% Annually through 2014; Maintains Expectations of 4-6\% Growth in 2010." Retrieved July 4, 2012. <http://www.imshealth.com>.

Law, M.R., L. Cheng, I.A. Dhalla, D. Heard and S. G. Morgan. 2012."The Effect of Cost on Adherence to Prescription Medications in Canada." Canadian Medical Association Journal 184(3): 297-302.

Law, M.R. and S.G. Morgan. 2011."Purchasing Prescription Drugs in Canada: Hang Together or Hang Separately." Healthcare Policy 6(4): 22-26.

Lexchin, J. 1993. "Pharmaceuticals, Patents, and Politics: Canada and Bill C-22." International Journal of Health Services 23(1): 147-60.

McLeod, L., B.G. Bereza, M. Shim and P. Grootendorst. 2011. "Financial Burden of Household Out-of-Pocket Expenditures for Prescription Drugs: Cross-Sectional Analysis Based on National Survey Data." Open Medicine 5(1): e1-e9. Retrieved July 4, 2012. <http://www.openmedicine.ca/article/download/381/369>.

Morgan, S. and M. Coombes. 2006. "Income-Based Drug Coverage in British Columbia: Toward an Understanding of the Policy." Healthcare Policy 2(2): 92-108. 


\section{Canadian Pharmacare}

Morgan, S. and C. Cunningham. 2008."The Effect of Evidence-Based Drug Coverage Policies on Pharmaceutical R\&D: A Case Study from British Columbia - Abridged Version." Healthcare Policy 3(3): 54-63.

Morgan, S.G. and D. Willison. 2004. “Post-Romanow Pharmacare: Last-Dollar First ... First-Dollar Lost?” HealthcarePapers 4(3): 10-20.

Mowery, D.C. 2004. Ivory Tower and Industrial Innovation: University-Industry Technology Transfer Before and After the Bayh-Dole Act in the United States. Stanford, CA: Stanford Business Books.

Ontario. 2012."A Fairer Drug System for Seniors." Retrieved July 4, 2012. <http://news.ontario.ca/mohltc/ en/2012/04/a-fairer-drug-system-for-seniors.html>.

Palmer D’Angelo Consulting. 1997. National Pharmacare Cost Impact Study. Ottawa: Author.

Patented Medicine Prices Review Board (PMPRB). 2012. Annual Report 2011. Ottawa: Author.

Pomey, M.-P., P.-G. Forest, H.A. Palley and E. Martin. 2007.“Public/Private Partnerships for Prescription Drug

Coverage: Policy Formulation and Outcomes in Quebec's Universal Drug Insurance Program, with Comparisons to the Medicare Prescription Drug Program in the United States." Milbank Quarterly 85(3): 469-98.

Rockoff, J.D. and J. Corbett Dooren. 2012 (February 1). “FDA Approves Cystic Fibrosis Drug.” Wall Street Journal. Retrieved July 4, 2012. <http://online.wsj.com/article/SB10001424052970204740904577195144014038270. html>.

Saskatchewan Health. 2010. Drug Plan and Extended Benefits Annual Report - 2009-2010. Retrieved July 4, 2012. $<$ http://www.health.gov.sk.ca/dpeb-annual-reports $>$.

Squires, D.A. 2011."The US Health System in Perspective: A Comparison of Twelve Industrialized Nations." Issue brief from The Commonwealth Fund. Issues in International Health Policy 16: 1-14. Retrieved July 4, 2012. $<$ http://www.commonwealthfund.org/Publications/Issue-Briefs/2011/Jul/US-Health-System-in-Perspective. aspx $>$.

Taylor, M.G. 2009. Health Insurance and Canadian Public Policy: The Seven Decisions That Created the Canadian Health Insurance System and Their Outcomes. Montreal: McGill-Queen's University Press.

Temin, P. 1980. Taking Your Medicine: Drug Regulation in the United States. Cambridge, MA: Harvard University Press. 